\title{
Risk of Hepatitis B Virus (HBV) Reactivation in Patients with Immune-Mediated Inflammatory Diseases Receiving Biologics: Focus on the Timing of Biologics after Anti-HBV Treatment
}

\author{
Soo Min Ahn', Jonggi Choi², Byong Duk Ye², Suk-Kyun Yang², Ji Seon Oh³ , Yong-Gil Kim¹, Chang-Keun Lee', Bin \\ Yoo', Sang Hyoung Park², and Seokchan Hong ${ }^{1}$
}

Departments of ${ }^{1}$ Rheumatology, ${ }^{2}$ Gastroenterology, and ${ }^{3}$ Information Medicine, Big Data Research Center, Asan Medical Center, University of Ulsan College of Medicine, Seoul, Korea

\section{Article Info}

Received May 8, 2021

Revised August 17, 2021

Accepted August 24, 2021

Published online November 29, 2021

\section{Corresponding Author}

Seokchan Hong

ORCID https://orcid.org/0000-0001-8722-3124

E-mail medivineluke@gmail.com

\section{Sang Hyoung Park}

ORCID https://orcid.org/0000-0002-5366-5749

E-mail shpark78@amc.seoul.kr
Background/Aims: Anti-hepatitis B virus (HBV) therapy is required for patients with HBV infection receiving biologics because of the high risk of HBV reactivation. However, it is unclear when to start biologics after anti-HBV treatment. We investigated the risk of HBV reactivation according to the timing of biologics initiation after anti-HBV treatment in immune-mediated inflammatory disease (IMID) patients with HBV infection.

Methods: We retrospectively evaluated the incidence of HBV reactivation in IMID patients who received biologics between July 2005 and April 2020. The patients were divided into two groups (within 1-week and after 1-week) according to the timing of biologics initiation after anti-HBV treatment. The cumulative probabilities and factors associated with HBV reactivation were evaluated.

Results: A total of 60 hepatitis B surface antigen-positive patients with IMID received biologics (within 1-week group, $n=23$ [38\%]; after 1-week group, $n=37$ [62\%]). During a median follow-up of 34 months (interquartile range, 20 to 74 months), three patients (5\%) developed HBV reactivation. In univariate analysis, the timing of biologics after anti-HBV treatment was not significantly associated with the risk of HBV reactivation (hazard ratio, 0.657; 95\% confidence interval, 0.059 to $7.327 ; p=0.733$ ). The cumulative probabilities of HBV reactivation did not significantly differ according to the timing of biologics $(p=0.731)$.

Conclusions: The risk of HBV reactivation was not significantly associated with the timing of biologics administration after anti-HBV treatment. Thus, biologics may be initiated early in patients with IMID undergoing treatment for HBV. (Gut Liver 2022;16:567-574)

Key Words: Hepatitis B virus; Biologics; Immune-mediated inflammatory disease; Tumor necrosis factor inhibitor

\section{INTRODUCTION}

Biologics such as anti-tumor necrosis factor (TNF)- $\alpha$ agents are widely used to treat patients with immunemediated inflammatory diseases (IMIDs) including rheumatoid arthritis, ankylosing spondylitis, Crohn's disease, and ulcerative colitis. ${ }^{1-3}$ The introduction of biologics led to significant improvements in the treatment of IMID, but has been shown to accompany increased risk of infection including the reactivation of latent tuberculosis infection. ${ }^{4,5}$

Hepatitis B virus (HBV), a hepatotropic DNA virus, can infect hepatocytes and reside inside the nucleus as a form of covalently closed circular DNA, which is responsible for the chronic and persistent nature of HBV infection. ${ }^{6}$ $\mathrm{HBV}$ infection is one of the major causes of chronic liver disease, which is a global public problem with a higher prevalence in Asian countries. ${ }^{7}$ In addition, with the recent widespread use of biologics, there has been attention to the reactivation of HBV in patients with IMID. Recent guidelines recommend that patients with HBV infectionparticularly those positive for hepatitis B surface antigen (HBsAg)—should receive anti-HBV treatment when us- 
ing biologics. ${ }^{8-12}$ However, it is not well established when anti-HBV treatment should be started before biologics use, although it is often suggested to administer anti-HBV agents at least 1 week before initiating immunosuppressive therapy. ${ }^{10,13}$

No studies to date have directly compared the risk of $\mathrm{HBV}$ reactivation according to the timing of biologics administration after the initiation of anti-HBV treatment. We hypothesized that the risk of HBV reactivation would not be high even if biologics were initiated after a relatively short HBV treatment period of less than 1 week. Therefore, we investigated whether biologics can be initiated early with anti-HBV agents in patients with IMIDs by comparing the incidence of $\mathrm{HBV}$ reactivation between patients who received biologics within 1 week and those who received it at least 1 week after anti-HBV treatment.

\section{MATERIALS AND METHODS}

\section{Patients}

In this retrospective cohort study, we reviewed the data of HBsAg-positive patients with IMIDs who were started on biologics between July 2005 and April 2020 at Asan Medical Center, a tertiary referral hospital in Seoul, Korea. The definition of IMID included the following diseases: rheumatoid arthritis, ankylosing spondylitis, ulcerative colitis, Crohn's disease, and other rheumatic diseases such as systemic lupus erythematosus and adult-onset Still's disease. The following data were collected from the electronic medical records: demographic information (sex, age, body mass index, comorbid diseases [hypertension, diabetes mellitus]), drug exposure (corticosteroids, azathioprine, disease-modifying anti-rheumatic drugs including methotrexate, sulfasalazine, and hydroxychloroquine) and baseline laboratory data (HBV DNA titers, HBV antibody profile, and aspartate aminotransferase, alanine aminotransferase, total bilirubin). Data on the type of anti-HBV agents were also collected.

Patients were classified into two groups (within 1-week group vs after 1-week group) according to the timing of biologics administration after initiating anti-HBV therapy. $\mathrm{HBV}$ reactivation is defined as increases in the HBV DNA titers by more than 100 -fold compared with the lowest level of HBV DNA titers or measurement of more than 1,000 $\mathrm{IU} / \mathrm{mL}$ in a patient with a previously undetectable level of HBV DNA. ${ }^{10}$

Patients were excluded if they had any of the following: positive serology for hepatitis $\mathrm{C}$ virus, human immunodeficiency virus, or a history of acute hepatitis A infection.

This study was approved by the Institutional Review
Board of Asan Medical Center (IRB number: 2020-1738). The requirement for informed consent was waived due to the retrospective design of the study.

\section{Statistical analysis}

The chi-square and the Fisher exact tests were used to compare categorical data. Continuous values are expressed as mean (standard deviations or as median [interquartile range]) and were compared using the Student t-test for parametric data and the Mann-Whitney $U$ test for nonparametric data. To identify the risk factors for HBV reactivation, the univariate Cox regression analyses were performed and the results are reported as hazard ratios (HRs) and 95\% confidence intervals (CIs). The cumulative probabilities of $\mathrm{HBV}$ reactivation were calculated using the Kaplan-Meier method and compared using the log-rank test. Statistical significance was set at $\mathrm{p}<0.05$. All statistical analyses were performed in IBM SPSS Statistics for Windows, version 21.0 (IBM Corp., Armonk, NY, USA).

\section{RESULTS}

\section{Baseline characteristics of patients with IMID and HBV infection receiving biologics}

A total of 60 IMID patients with HBsAg-positive were included in this study. The baseline clinical and laboratory data of the patients are summarized in Table 1. The mean age was $47.7 \pm 10.4$ years and 32 patients $(53.3 \%)$ were female. The most common type of IMID was rheumatoid arthritis (38.3\%), followed by Crohn's disease (33.3\%), ulcerative colitis (13.3\%), and ankylosing spondylitis (11.7\%). Of the biologics, anti-TNF- $\alpha$ agents (17 etanercept, 18 infliximab, 18 adalimumab, and two golimumab) were administered to 55 patients (91.7\%).

Of the total patients, 23 patients (38.3\%) were started on biologics within 1 week of anti-HBV treatment initiation and were thus included in the "within 1-week group," and the remaining 37 patients $(61.7 \%)$ were included in the "after 1-week group." The majority of patients (78.3\%) in the within 1-week group received biologics and anti-HBV agents at the same time. The mean age at the treatment of biologics was significantly younger in the within 1-week group than in the after 1-week group (43.8 years vs 50.1 years, $\mathrm{p}=0.022$ ). The distribution of the types of IMID was significantly different between the two groups $(\mathrm{p}=0.030)$, whereas there were no significant differences in the biologics and medications including corticosteroids and diseasemodifying anti-rheumatic drugs. There were no significant differences in the HBV serology and liver function test results between the two groups, except the baseline median 
Table 1. Clinical Characteristics of the Study Patients

\begin{tabular}{|c|c|c|c|c|}
\hline Characteristics & $\begin{array}{l}\text { Total } \\
(\mathrm{n}=60)\end{array}$ & $\begin{array}{l}\text { Within 1-week group } \\
\qquad(\mathrm{n}=23)\end{array}$ & $\begin{array}{l}\text { After 1-week group } \\
\qquad(\mathrm{n}=37)\end{array}$ & $\mathrm{p}$-value \\
\hline Age, yr & $47.7 \pm 10.4$ & $43.8 \pm 10.0$ & $50.1 \pm 10.0$ & 0.022 \\
\hline Female sex & 32 (53.3) & 15 (65.2) & 17 (45.9) & 0.146 \\
\hline $\mathrm{BMI}, \mathrm{kg} / \mathrm{m}^{2}$ & $22.9 \pm 3.8$ & $22.8 \pm 4.6$ & $23.0 \pm 3.3$ & 0.785 \\
\hline IMIDs & & & & 0.030 \\
\hline Rheumatoid arthritis & 23 (38.3) & $9(39.1)$ & 14 (37.8) & \\
\hline Ankylosing spondylitis & 7 (11.7) & $5(21.7)$ & $2(5.4)$ & \\
\hline Crohn's disease & 20 (33.3) & $9(39.1)$ & $11(29.7)$ & \\
\hline Ulcerative colitis & 8 (13.3) & 0 & $8(21.6)$ & \\
\hline Others & $2(3.3)$ & 0 & $2(5.4)$ & \\
\hline Biologics & & & & 0.593 \\
\hline Anti-TNF-a agents & 55 (91.7) & $22(95.7)$ & 33 (89.2) & \\
\hline Etanercept & $17(28.3)$ & $7(30.4)$ & $10(27.0)$ & \\
\hline Infliximab & $18(30.0)$ & $4(17.4)$ & $14(37.8)$ & \\
\hline Adalimumab & $18(30.0)$ & $10(43.5)$ & $8(21.6)$ & \\
\hline Golimumab & 2 (3.3) & $1(4.3)$ & $1(2.7)$ & \\
\hline Tocilizumab & 2 (3.3) & 0 & $2(5.4)$ & \\
\hline Rituximab & $1(1.7)$ & 0 & $1(2.7)$ & \\
\hline Ustekinumab & $1(1.7)$ & 0 & $1(2.7)$ & \\
\hline Tofacitinib & $1(1.7)$ & $1(4.3)$ & 0 & \\
\hline Corticosteroids & 31 (51.7) & $9(39.1)$ & 22 (59.5) & 0.126 \\
\hline Prednisolone, mg/day & $2.5(0-10)$ & $0(0-10)$ & $5.0(0-20)$ & 0.053 \\
\hline Prednisolone $\geq 10$ mg/day & $21(35.0)$ & $6(26.1)$ & $15(40.5)$ & 0.254 \\
\hline Anti-inflammatory drugs & 29 (48.3) & $11(47.8)$ & $18(48.6)$ & 0.951 \\
\hline DMARDs & $21(35.0)$ & 8 (34.8) & $13(35.1)$ & 0.978 \\
\hline Azathioprine & 8 (13.3) & $3(13.0)$ & 5 (13.5) & 1.000 \\
\hline \multicolumn{5}{|l|}{ Comorbidities } \\
\hline Hypertension & 5 (8.3) & 0 & $5(13.5)$ & 0.146 \\
\hline Diabetes mellitus & $3(5.0)$ & $2(8.7)$ & $1(2.7)$ & 0.552 \\
\hline \multicolumn{5}{|l|}{ Liver-related characteristics } \\
\hline Cirrhosis & $8(13.3)$ & $1(4.3)$ & $7(18.9)^{*}$ & 0.138 \\
\hline Decompensated cirrhosis & $2(28.6)$ & 0 & 2 (33.3) & 1.000 \\
\hline \multicolumn{5}{|c|}{ Laboratory findings (at anti-HBV agent initiation) } \\
\hline HBV DNA, IU/mL & $\begin{array}{c}5.5 \times 10^{3} \\
\left(2.6 \times 10^{2}-7.6 \times 10^{7}\right)\end{array}$ & $\begin{array}{c}5.4 \times 10^{2} \\
\left(2.0 \times 10^{2}-5.6 \times 10^{5}\right)\end{array}$ & $\begin{array}{c}5.7 \times 10^{6} \\
\left(4.0 \times 10^{2}-2.0 \times 10^{8}\right)\end{array}$ & 0.071 \\
\hline ALT, IU/L & $28(12-101)$ & $18(12-32)$ & $87(11-142)$ & 0.048 \\
\hline AST, IU/L & $27(19-86)$ & $23(18-28)$ & $58(19-112)$ & 0.008 \\
\hline Total bilirubin, mg/dL & $0.6(0.4-0.9)$ & $0.6(0.4-0.7)$ & $0.7(0.4-0.9)$ & 0.108 \\
\hline \multicolumn{5}{|c|}{ Baseline laboratory findings (at biologics initiation) } \\
\hline HBeAg positive & $15(25.0)$ & $7(30.4)$ & $8(21.6)$ & 0.443 \\
\hline HBV DNA, IU/mL & $\begin{array}{c}2.1 \times 10^{2} \\
\left(0^{+}-4.6 \times 10^{3}\right)\end{array}$ & $\begin{array}{c}5.4 \times 10^{2} \\
\left(2.0 \times 10^{2}-5.6 \times 10^{5}\right)\end{array}$ & $\begin{array}{c}3.7 \times 10^{1} \\
\left(0^{+}-4.3 \times 10^{2}\right)\end{array}$ & 0.001 \\
\hline HBV DNA $(>2,000 \mathrm{IU} / \mathrm{mL})$ & $15(25.0)$ & $9(39.1)$ & $6(16.2)$ & 0.046 \\
\hline$A L T, I U / L$ & $22(18-28)$ & $18(13-29)$ & $14(10-24)$ & 0.088 \\
\hline AST, IU/L & $14.5(11-24)$ & $25.0(18-25)$ & $21.0(18-30)$ & 0.428 \\
\hline Total bilirubin, mg/dL & $0.6 \pm 0.2$ & $0.6 \pm 0.2$ & $0.5 \pm 0.2$ & 0.527 \\
\hline
\end{tabular}

Data are presented as the mean $\pm \mathrm{SD}$, number (\%), or median (interquartile range).

BMI, body mass index; IMID, immune-mediated inflammatory disease; TNF, tumor necrosis factor; DMARDs, disease-modifying anti-rheumatic drugs; HBV, hepatitis B virus; ALT, alanine aminotransferase; AST, aspartate aminotransferase; HBeAg, hepatitis B e antigen.

*Including hepatocellular carcinoma $(\mathrm{n}=1) ;{ }^{\dagger}$ Undetectable serum HBV DNA.

HBV DNA titers were higher in the within 1-week group $\left(5.4 \times 10^{2} \mathrm{IU} / \mathrm{mL}\right.$ vs $\left.3.7 \times 10^{1} \mathrm{IU} / \mathrm{mL}, \mathrm{p}=0.001\right)$.

\section{Development of HBV reactivation}

Table 2 shows the occurrence of HBV reactivation during biologic treatment with anti-HBV therapy. Followup duration was significantly longer in the within 1-week group than in the after 1-week group (50.0 months [interquartile range, 31 to 86 ] vs 25.0 months [interquartile range, 17 to 70$], \mathrm{p}=0.026)$. The most common antiviral agents prescribed for HBV were entecavir $(41.7 \%)$ and tenofovir (41.7\%), followed by lamivudine $(15.0 \%)$ and telbivudine (1.7\%). The types of anti-HBV agents were not significantly different between the two groups $(\mathrm{p}=0.222)$. 
Table 2. Treatment and HBV Reactivation during Follow-up

\begin{tabular}{|c|c|c|c|c|}
\hline Variable & $\begin{array}{l}\text { Total } \\
(n=60)\end{array}$ & $\begin{array}{l}\text { Within 1-week group } \\
\qquad(n=23)\end{array}$ & $\begin{array}{l}\text { After 1-week group } \\
\qquad(\mathrm{n}=37)\end{array}$ & p-value \\
\hline Follow-up duration, median (IQR), mo & $34(20-74)$ & $50(31-86)$ & $25(17-70)$ & 0.026 \\
\hline Duration from HBV treatment to initiation of biologics, median (IQR), day & $32(0-433)$ & $0(0-0)$ & $387(35-688)$ & $<0.001$ \\
\hline Antiviral agents, No. (\%) & & & & 0.222 \\
\hline Entecavir & 25 (41.7) & $9(39.1)$ & $16(43.2)$ & \\
\hline Tenofovir & 25 (41.7) & $8(34.8)$ & 17 (45.9) & \\
\hline Lamivudine & $9(15.0)$ & $6(26.1)$ & $3(8.1)$ & \\
\hline Telbivudine & $1(1.7)$ & 0 & $1(2.7)$ & \\
\hline Development of HBV reactivation, No. (\%) & $3(5.0)$ & $1(4.3)$ & $2(5.4)$ & 1.000 \\
\hline
\end{tabular}

HBV, hepatitis B virus; IQR, interquartile range.

Table 3. Clinical Characteristics of the Three Patients with HBV Reactivation after Starting Biologics

\begin{tabular}{|c|c|c|c|}
\hline Characteristics & Patient 1 & Patient 2 & Patient 3 \\
\hline Age, yr/sex & 49/M & $21 / M$ & $54 / F$ \\
\hline Time to initiation of biologics after initiating antiviral agent for HBV, day & 433 & 696 & 0 \\
\hline Time to HBV reactivation after initiation of biologics, mo & 7 & 25 & 8 \\
\hline Indication for biologics & RA & CD & RA \\
\hline Biological agent & Anti-TNF-a agent (ETN) & Anti-TNF-a agent (ADA) & Anti-TNF-a agent (ADA) \\
\hline Antiviral agent at baseline & Lamivudine & Tenofovir & Lamivudine \\
\hline Concomitant steroids (dose) & None & None & Yes (10 mg) \\
\hline Concomitant anti-inflammatory drugs & $\mathrm{SSZ}, \mathrm{HCQ}$ & AZA & $\mathrm{HCQ}$ \\
\hline HBV DNA titer (at anti-HBV agent initiation), IU/mL & $2.2 \times 10^{7}$ & $7.5 \times 10^{7}$ & $5.6 \times 10^{5}$ \\
\hline \multicolumn{4}{|l|}{ Baseline laboratory findings (at biologics initiation) } \\
\hline $\mathrm{HBsAg} / \mathrm{HBsAb}$ & Positive/negative & Positive/negative & Positive/negative \\
\hline $\mathrm{HBeAg} / \mathrm{HBeAb}$ & Negative/negative & Positive/negative & Positive/negative \\
\hline HBV DNA titer, IU/mL & $2.5 \times 10^{4}$ & $1.1 \times 10^{3}$ & $5.6 \times 10^{5}$ \\
\hline$A L T, I U / L$ & 13 & 51 & 13 \\
\hline AST, IU/L & 26 & 31 & 44 \\
\hline Total bilirubin, mg/dL & 0.6 & 0.5 & 0.8 \\
\hline HBV DNA titer (lowest level), IU/mL & $2.5 \times 10^{4}$ & $<15$ & $2.2 \times 10^{3}$ \\
\hline \multicolumn{4}{|l|}{ At HBV reactivation laboratory findings } \\
\hline HBV DNA titer, IU/mL & $1.6 \times 10^{8}$ & $6.4 \times 10^{4}$ & $5.4 \times 10^{7}$ \\
\hline$A L T, I U / L$ & 30 & 523 & 54 \\
\hline AST, IU/L & 38 & 384 & 61 \\
\hline Total bilirubin, mg/dL & 0.9 & 0.7 & 1.0 \\
\hline Lamivudine resistance & Positive & Negative & Positive \\
\hline Biologics stopped or interrupted due to HBV reactivation & Yes & No & No \\
\hline Outcome & $\begin{array}{c}\text { Recovered } \\
\text { (lamivudine change to } \\
\text { entecavir) }\end{array}$ & Recovered & $\begin{array}{c}\text { Recovered } \\
\text { (lamivudine change to } \\
\text { adefovir) }\end{array}$ \\
\hline
\end{tabular}

HBV, hepatitis B virus; M, male; F, female; RA, rheumatoid arthritis; CD, Crohn's disease; TNF, tumor necrosis factor; ETN, etanercept; ADA, adalimumab; SSZ, sulfasalazine; HCQ, hydroxychloroquine; AZA, azathioprine; HBsAg, hepatitis B surface antigen; HBsAb, hepatitis B surface antibody; HBeAg, hepatitis B e antigen; HBeAb, hepatitis B e antibody; ALT, alanine aminotransferase; AST, aspartate aminotransferase.

Of the total of 60 patients, HBV reactivation occurred in three (5.0\%). The crude rates of HBV reactivation did not significantly differ between the within 1-week group $(\mathrm{n}=1$, $4.3 \%)$ and the after 1-week group $(\mathrm{n}=2,5.4 \%)(\mathrm{p}=1.000)$. Details of the clinical and laboratory characteristics of the three patients with HBV reactivation are shown in Table 3. The time to HBV reactivation after the initiation of biologics was 7 to 25 months. Two patients did not discontinue biologics, and one of them changed the anti-HBV agent from lamivudine to adefovir. All three patients recovered from HBV reactivation without long-term liver abnormalities.

\section{Factors related to HBV reactivation}

Next, we performed a Cox regression analysis to identify the factors associated with $\mathrm{HBV}$ reactivation in patients under treatment with biologics (Table 4). The results of this analysis showed that HBV reactivation was not significantly associated with age, sex, prednisolone dose, diseasemodifying anti-rheumatic drug use, and high HBV DNA titer at baseline. Interestingly, the use of lamivudine was significantly associated with the risk of HBV reactivation (HR, 11.330; 95\% CI, 1.026 to 125.059; $\mathrm{p}=0.048$ ). Also, liver cirrhosis was significantly associated with the risk of 
HBV reactivation (HR, 20.431; 95\% CI, 1.756 to 237.775 ; $\mathrm{p}=0.016$ ). In contrast, the initiation of biologics within 1 week of anti-HBV treatment was not significantly associated with the risk of $\mathrm{HBV}$ reactivation (HR, 0.657; 95\% CI, 0.059 to $7.327 ; \mathrm{p}=0.733$ ). In addition, the Kaplan-Meier analysis showed that the cumulative probabilities of HBV reactivation did not significantly differ according to the timing of biologics initiation ( $\leq 1$ week and $>1$ week) after anti-HBV therapy ( $\mathrm{p}=0.731)$ (Fig. 1).

\section{DISCUSSION}

The present study showed HBV reactivation in patients with IMID under biologic treatments after anti-HBV therapy was not common, with a crude rate of 5\% (3/60). Interestingly, we also found that early initiation ( $\leq 1$ week) of biologics after starting anti-HBV agent was not significantly associated with a higher risk of $\mathrm{HBV}$ reactivation (HR, 0.657; 95\% CI, 0.059 to 7.327; $\mathrm{p}=0.733$ ).

$\mathrm{HBV}$ can persist inside the nucleus of hepatocytes for a long-time even if only trace amounts of HBV particles are present in the peripheral blood, ${ }^{6}$ and the natural course of $\mathrm{HBV}$ infection is determined by the interaction between the virus and host immune responses. Thus, suppression of host immunity by immunosuppressive therapy including anti-cancer drugs increases the risk of HBV reactivation. ${ }^{14}$ Furthermore, a high risk of HBV reactivation has been reported in patients with IMID with the introduction and widespread use of biologics such as anti-TNF- $\alpha$ agents. ${ }^{15-20}$ Even though the rates of $\mathrm{HBV}$ reactivation were previously reported to be lower in patients receiving biologics than in those treating cancer chemotherapy, ${ }^{21}$ the rate of $\mathrm{HBV}$ reactivation has been reported to be up to $39 \%$ in HBsAg-positive patients during treatment with antiTNF- $\alpha$ agents. ${ }^{17,22}$ Anti-HBV treatment is beneficial for reducing the risk of $\mathrm{HBV}$ reactivation in patients receiving chemotherapy as well as in those exposed to biologics. ${ }^{17,23}$ The observed rate of HBV reactivation in our study (3/60, $5 \%$ ) was similar to those reported from previous studies on HBsAg-positive patients with IMID receiving biologics and anti-HBV therapy. ${ }^{24,25}$

Several HBV guidelines recommended that anti-HBV treatment should be initiated before starting biologics, including anti-TNF- $\alpha$ agents for patients with HBsAg. ${ }^{8-11}$ However, the optimal timing for initiating biologics after anti-HBV therapy remains uncertain. Indeed, the guidelines do not specify the appropriate timing for starting the biologics after anti-HBV therapy. ${ }^{8,9,11}$ Although the American Association for the Study of Liver Diseases guideline mentions that anti-HBV agents should be administered

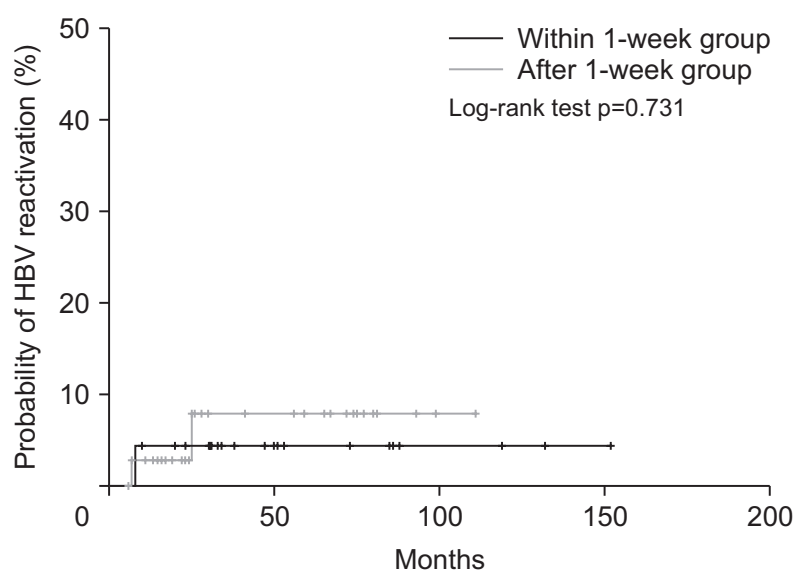

Fig. 1. Cumulative probability of hepatitis $B$ virus (HBV) reactivation according to the time of initiation of biologics after HBV treatment.

Table 4. Univariate Cox Proportional Hazards Regression Analysis for the Risk of HBV Reactivation

\begin{tabular}{lcc}
\hline \multicolumn{1}{c}{ Variable } & HR $(95 \% \mathrm{Cl})$ & $\mathrm{p}$-value \\
\hline Biologics initiated within 1 week & $0.657(0.059-7.327)$ & 0.733 \\
Male sex & $2.196(0.199-24.250)$ & 0.521 \\
Age & $0.946(0.854-1.048)$ & 0.286 \\
IBD & $0.575(0.052-6.341)$ & 0.651 \\
Anti-TNF-a use & $22.743(0-\mathrm{NA})$ & 0.747 \\
Lamivudine use & $11.330(1.026-125.059)$ & 0.048 \\
Prednisolone dose & $0.949(0.790-1.136)$ & 0.566 \\
DMARDs use & $3.581(0.325-39.506)$ & 0.298 \\
Azathioprine use & $2.961(0.268-32.704)$ & 0.376 \\
HBV DNA (>2,000 IU/mL) & $6.691(0.604-74.105)$ & 0.121 \\
ALT & $0.999(0.963-1.037)$ & 0.977 \\
AST & $1.011(0.967-1.058)$ & 0.629 \\
Total bilirubin & $4.069(0.031-427.854)$ & 0.572 \\
Liver cirrhosis & $20.431(1.756-237.775)$ & 0.016 \\
\hline
\end{tabular}

HBV, hepatitis B virus; HR, hazard ratio; Cl, confidence interval; IBD, inflammatory bowel disease; TNF, tumor necrosis factor; DMARDs, diseasemodifying anti-rheumatic drugs; ALT, alanine aminotransferase; AST, aspartate aminotransferase; NA, not aviliable. 
7 days before the onset of anti-cancer drugs or immunosuppressants, ${ }^{10}$ the supporting evidence for this statement was very limited because of the lack of comparative study on the timing of biologics administration. ${ }^{23}$ In our present study, one out of the 23 patients in the "within 1-week group" developed HBV reactivation, whereas two of the 37 patients in the "after 1-week group" developed HBV reactivation. In addition, results from the Cox regression and the Kaplan-Meier analysis showed that early initiation $(<1$ week) of biologics after anti-HBV therapy was not significantly associated with the risk of HBV reactivation (Table 4, Fig. 1). Interestingly, the majority $(18 / 23,78 \%)$ of patients in the "within 1-week group" initiated biologics and antiHBV agents simultaneously, and only one of them experienced HBV reactivation during follow-up. These findings suggest that biologics may be initiated at any time within 1 week of commencing HBV treatment without increasing the risk of $\mathrm{HBV}$ reactivation.

Regarding the regimen of anti-HBV agents, most recent guidelines recommend tenofovir and entecavir as the first-line drug, whereas first-generation drugs such as lamivudine are not recommended as first-line treatment for patients with HBV because of high viral resistance to this drug. ${ }^{8-11,26}$ Several previous studies have shown that entecavir and tenofovir are more potent than lamivudine and have a higher genetic barrier to HBV resistance. ${ }^{21,23,27,28}$ It has also been shown that more than $60 \%$ of drug resistance occurs when lamivudine is used as an anti-HBV agent over 5 years. ${ }^{29}$ There have been several reports of HBV reactivation due to resistance to lamivudine when it is used as an anti-HBV agent for chronic HBV infection. ${ }^{24,30,31}$ Similarly, in our study, two out of the three patients with HBV reactivation had been treated with lamivudine, and lamivudine resistance was confirmed as shown by HBV reverse transcriptase gene mutation analysis at the time of $\mathrm{HBV}$ reactivation. These two patients had decreased HBV DNA titers after changing to other anti-HBV agents (entecavir and adefovir) despite continuing the biologics. In addition, considering the results from the univariate analysis, it is likely that lamivudine use was associated with the increased risk of HBV reactivation. Additionally, underlying cirrhosis was present in the two patients for whom lamivudine resistance was confirmed. Liver cirrhosis is also a risk factor for HBV reactivation, particularly in association with immunosuppressive therapy. ${ }^{32}$

In our study, only one of three patients with HBV reactivation discontinued biologics. The determination to discontinue or maintain biologics at HBV reactivation was based on the physician's discretion. Indeed, there is no treatment guideline regarding how to use biologics upon or after HBV reactivation. Thus, further research inves- tigating treatment strategies for use of biologics upon or after HBV reactivation are needed.

The present study had some limitations. First, this study may have been affected by selection bias inherent to its retrospective and single-center design. The retrospective nature of the study meant that $\mathrm{HBV}$ reactivation due to poor drug compliance could not be completely ruled out. Second, multivariable analysis could not be performed due to the small number of patients. Third, our study included patients who had already taken anti-HBV agents due to exacerbation of HBV, as well as those who had started antiviral therapy at the time of biologics initiation. Therefore, future studies are warranted that only include patients who have already started HBV treatment when they start biologics treatment or are expecting to start biologics treatment. Despite these limitations, this is the first study to compare the occurrence of $\mathrm{HBV}$ reactivation according to the time of biologics administration after the start of antiHBV agents in patients with IMID.

In conclusion, this study showed that the rate of HBV reactivation was not significantly different according to the timing of biologics administration after anti-HBV therapy. Thus, our results suggest that biologics may be initiated early ( $\leq 1$ week) after anti-HBV therapy in HBsAg-positive patients with IMID.

\section{CONFLICTS OF INTEREST}

No potential conflict of interest relevant to this article was reported.

\section{ACKNOWLEDGEMENTS}

This research was supported by the Bio \& Medical Technology Development Program of the National Research Foundation (NRF) and funded by the Korean government (MSIT) (number: 2018M3A9D3079500).

\section{AUTHOR CONTRIBUTIONS}

Study conception and design: S.M.A., S.H.P., S.H. Acquisition of data: S.M.A., J.C., B.D.Y., S.K.Y., J.S.O., Y.G.K., C.K.L., B.Y., S.H.P., S.H. Stastical analysis and interpretation of data: S.M.A., J.C., J.S.O., Y.G.K., C.K.L., B.Y., S.H.P., S.H. Drafting of the manuscript: S.M.A., S.H. Critical revision of the manuscript for important intellectual content: J.C., S.H.P., S.H. 


\section{ORCID}

Soo Min Ahn

Jonggi Choi

Byong Duk Ye

Suk-Kyun Yang

Ji Seon Oh

Yong-Gil Kim

Chang-Keun Lee

Bin Yoo

Sang Hyoung Park

Seokchan Hong https://orcid.org/0000-0002-9213-9768

https://orcid.org/0000-0002-7470-5850

https://orcid.org/0000-0001-6647-6325

https://orcid.org/0000-0003-2772-2575

https://orcid.org/0000-0002-0205-6492

https://orcid.org/0000-0002-8029-7355

https://orcid.org/0000-0003-3653-7515

https://orcid.org/0000-0002-1836-5273

https://orcid.org/0000-0002-5366-5749

https://orcid.org/0000-0001-8722-3124

\section{REFERENCES}

1. Kuek A, Hazleman BL, Ostör AJ. Immune-mediated inflammatory diseases (IMIDs) and biologic therapy: a medical revolution. Postgrad Med J 2007;83:251-260.

2. Ooi CJ, Hilmi I, Banerjee R, et al. Best practices on immunomodulators and biologic agents for ulcerative colitis and Crohn's disease in Asia. Intest Res 2019;17:285-310.

3. Fukuda T, Naganuma M, Kanai T. Current new challenges in the management of ulcerative colitis. Intest Res 2019;17:3644.

4. Gómez-Reino JJ, Carmona L, Valverde VR, Mola EM, Montero MD; BIOBADASER Group. Treatment of rheumatoid arthritis with tumor necrosis factor inhibitors may predispose to significant increase in tuberculosis risk: a multicenter active-surveillance report. Arthritis Rheum 2003;48:21222127.

5 . Ye BD, Travis S. Improving the quality of care for inflammatory bowel disease. Intest Res 2019;17:45-53.

6. Seto WK, Lo YR, Pawlotsky JM, Yuen MF. Chronic hepatitis B virus infection. Lancet 2018;392:2313-2324.

7. Schweitzer A, Horn J, Mikolajczyk RT, Krause G, Ott JJ. Estimations of worldwide prevalence of chronic hepatitis B virus infection: a systematic review of data published between 1965 and 2013. Lancet 2015;386:1546-1555.

8. Reddy KR, Beavers KL, Hammond SP, Lim JK, Falck-Ytter YT; American Gastroenterological Association Institute. American Gastroenterological Association Institute guideline on the prevention and treatment of hepatitis B virus reactivation during immunosuppressive drug therapy. Gastroenterology 2015;148:215-219.

9. Sarin SK, Kumar M, Lau GK, et al. Asian-Pacific clinical practice guidelines on the management of hepatitis B: a 2015 update. Hepatol Int 2016;10:1-98.

10. Terrault NA, Lok ASF, McMahon BJ, et al. Update on prevention, diagnosis, and treatment of chronic hepatitis B: AASLD 2018 hepatitis B guidance. Hepatology 2018;67:1560-1599.
11. European Association for the Study of the Liver. EASL 2017 Clinical Practice Guidelines on the management of hepatitis B virus infection. J Hepatol 2017;67:370-398.

12. Park SK, Choi CH, Chun J, et al. Prevention and management of viral hepatitis in inflammatory bowel disease: a clinical practice guideline by the Korean Association for the Study of Intestinal Diseases. Intest Res 2020;18:18-33.

13. Lau CS, Chia F, Dans L, et al. 2018 update of the APLAR recommendations for treatment of rheumatoid arthritis. Int J Rheum Dis 2019;22:357-375.

14. Gupta S, Govindarajan S, Fong TL, Redeker AG. Spontaneous reactivation in chronic hepatitis B: patterns and natural history. J Clin Gastroenterol 1990;12:562-568.

15. Esteve M, Saro C, González-Huix F, Suarez F, Forné M, Viver JM. Chronic hepatitis B reactivation following infliximab therapy in Crohn's disease patients: need for primary prophylaxis. Gut 2004;53:1363-1365.

16. Loras C, Gisbert JP, Saro MC, et al. Impact of surveillance of hepatitis $\mathrm{B}$ and hepatitis $\mathrm{C}$ in patients with inflammatory bowel disease under anti-TNF therapies: multicenter prospective observational study (REPENTINA 3). J Crohns Colitis 2014;8:1529-1538.

17. Pérez-Alvarez R, Díaz-Lagares C, García-Hernández F, et al. Hepatitis $B$ virus (HBV) reactivation in patients receiving tumor necrosis factor (TNF)-targeted therapy: analysis of 257 cases. Medicine (Baltimore) 2011;90:359-371.

18. Tamori A, Koike T, Goto H, et al. Prospective study of reactivation of hepatitis $\mathrm{B}$ virus in patients with rheumatoid arthritis who received immunosuppressive therapy: evaluation of both HBsAg-positive and HBsAg-negative cohorts. J Gastroenterol 2011;46:556-564.

19. Lee JI. Reactivation of hepatitis B virus in patients with rheumatologic disease treated with biologic disease modifying anti-rheumatic drugs: screening and treatment. J Rheum Dis 2015;22:282-287.

20. Park EJ, Choi KS, Song BC. Reactivation of hepatitis B virus and its prevention in patients with rheumatic diseases receiving immunosuppressive therapy. J Rheum Dis 2017;24:261270.

21. Perrillo RP, Gish R, Falck-Ytter YT. American Gastroenterological Association Institute technical review on prevention and treatment of hepatitis B virus reactivation during immunosuppressive drug therapy. Gastroenterology 2015;148:221244.

22. Lee $\mathrm{YH}$, Bae SC, Song GG. Hepatitis B virus reactivation in HBsAg-positive patients with rheumatic diseases undergoing anti-tumor necrosis factor therapy or DMARDs. Int J Rheum Dis 2013;16:527-531.

23. Zhang MY, Zhu GQ, Shi KQ, et al. Systematic review with network meta-analysis: comparative efficacy of oral nucleos $(t)$ ide analogues for the prevention of chemother- 
apy-induced hepatitis B virus reactivation. Oncotarget 2016;7:30642-30658.

24. Vassilopoulos D, Apostolopoulou A, Hadziyannis E, et al. Long-term safety of anti-TNF treatment in patients with rheumatic diseases and chronic or resolved hepatitis B virus infection. Ann Rheum Dis 2010;69:1352-1355.

25. Ryu HH, Lee EY, Shin K, et al. Hepatitis B virus reactivation in rheumatoid arthritis and ankylosing spondylitis patients treated with anti-TNFa agents: a retrospective analysis of 49 cases. Clin Rheumatol 2012;31:931-936.

26. Korean Association for the Study of the Liver (KASL). KASL clinical practice guidelines for management of chronic hepatitis B. Clin Mol Hepatol 2019;25:93-159.

27. Yu S, Luo H, Pan M, et al. Comparison of entecavir and lamivudine in preventing HBV reactivation in lymphoma patients undergoing chemotherapy: a meta-analysis. Int J Clin Pharm 2016;38:1035-1043.
28. Yang C, Qin B, Yuan Z, Chen L, Zhou HY. Meta-analysis of prophylactic entecavir or lamivudine against hepatitis B virus reactivation. Ann Hepatol 2016;15:501-511.

29. Lok AS, Lai CL, Leung N, et al. Long-term safety of lamivudine treatment in patients with chronic hepatitis B. Gastroenterology 2003;125:1714-1722.

30. Carroll MB, Bond MI. Use of tumor necrosis factor-alpha inhibitors in patients with chronic hepatitis B infection. Semin Arthritis Rheum 2008;38:208-217.

31. Pauly MP, Tucker LY, Szpakowski JL, et al. Incidence of hepatitis $\mathrm{B}$ virus reactivation and hepatotoxicity in patients receiving long-term treatment with tumor necrosis factor antagonists. Clin Gastroenterol Hepatol 2018;16:1964-1973.

32. Loomba R, Liang TJ. Hepatitis B reactivation associated with immune suppressive and biological modifier therapies: current concepts, management strategies, and future directions. Gastroenterology 2017;152:1297-1309. 